\title{
Role of CCL20/CCR6 and the ERK signaling pathway in lung adenocarcinoma
}

\author{
XIAO-PENG ZHANG ${ }^{1}$, ZHI-JUAN HU ${ }^{2}$, AI-HONG MENG ${ }^{3}$, GUO-CHEN DUAN ${ }^{1}$, \\ QING-TAO ZHAO ${ }^{1}$ and JING YANG ${ }^{4}$
}

\author{
Departments of ${ }^{1}$ Thoracic Surgery and ${ }^{2}$ Nephrology, Hebei General Hospital, Shijiazhuang, Hebei 050051; \\ ${ }^{3}$ Respiratory Division, The Second Hospital of Hebei Medical University, Shijiazhuang, Hebei 050050; \\ ${ }^{4}$ Respiratory Division, Hebei General Hospital, Shijiazhuang, Hebei 050051, P.R. China
}

Received November 25, 2015; Accepted May 8, 2017

DOI: $10.3892 / \mathrm{ol} .2017 .7253$

\begin{abstract}
Previous studies have revealed that carcinoma-associated fibroblasts communicate microenvironment-derived signals through chemokine/chemokine receptor interaction, resulting in carcinogenesis. $\mathrm{C}-\mathrm{C}$ motif chemokine ligand 20 (CCL20)/C-C motif chemokine receptor 6 (CCR6) interactions are involved in the pathogenesis of colonic malignancies. The present study aimed to characterize the roles of CCL20/CCR6 and the extracellular signal-regulated kinase (ERK) signaling pathway in lung adenocarcinoma growth. Lung adenocarcinoma samples obtained at surgery were assessed for the expression, tissue localization and production of CCL20/CCR6. In addition, colony formation, ERK signaling and chemokine production were measured to assess the responsiveness of the A549 cell line to CCL20 stimulation. CCL20 and CCR6 were found to be highly expressed in the majority of samples in the recurrence group (76 and 66\%, respectively). The staining indexes of CCL20 and CCR6 in the recurrence group were 149.3 and 134.4, respectively, which were significantly higher than those in the non-recurrence group (57.2 and 58.0, respectively); the protein and mRNA expression levels determined by western blot and reverse transcription-quantitative polymerase chain reaction were also found to be high in the recurrence group For A549 cells, the colony-forming capacity was increased by CCL20 stimulation, and this effect was dependent in part on ERK phosphorylation. Collectively, the findings suggest that CCR6 and CCL20 may serve a role in lung adenocarcinoma, leading to proliferation and migration via autocrine or paracrine mechanisms. The
\end{abstract}

Correspondence to: Dr Xiao-Peng Zhang, Department of Thoracic Surgery, Hebei General Hospital, 348 Heping West Road, Shijiazhuang, Hebei 050051, P.R. China

E-mail: 13722865878@163.com

Key words: lung adenocarcinoma, C-C motif chemokine ligand 20, $\mathrm{C}-\mathrm{C}$ motif chemokine receptor 6 , extracellular signal-regulated kinase, recurrence disruption of CCL20/CCR6 interactions may be a promising strategy for the treatment of cancer.

\section{Introduction}

Lung carcinomas, the second most frequent type of cancer worldwide, are the leading cause of cancer-associated mortality (1). Lung adenocarcinoma is a major pathological type of non-small cell lung cancer (NSCLC), which usually occurs following chronic inflammation $(2,3)$.

Chemokines are a superfamily of small chemotactic cytokines, which exert various biological functions by activating 7-transmembrane-domain $\mathrm{G}$ protein-coupled receptors on their target cells (4). Chemokines and their receptors are expressed by numerous types of neoplastic cells $(5,6)$. In tumor tissues, chemokines and chemokine receptors promote tumor growth, angiogenesis and escape of antitumor immune surveillance via autocrine and paracrine mechanisms $(6,7)$.

C-C motif chemokine ligand 20 (CCL20), alternatively termed liver and activation-regulated chemokine, is the only chemokine known to interact with $\mathrm{C}-\mathrm{C}$ motif chemokine receptor 6 (CCR6), a property shared with the antimicrobial $\beta$-defensins (8). The ligand-receptor pair CCL20/CCR6 is responsible for the chemoattraction of immature dendritic cells, effector/memory $\mathrm{T}$ cells and $\mathrm{B}$ cells, and also serves a role in the skin and mucosal surfaces under homeostatic and inflammatory conditions, as well as in pathological processes, such as those associated with cancer and rheumatoid arthritis (8). Furthermore, CCL20/CCR6 is involved in the pathogenesis of interstitial lung fibrosis and chronic obstructive pulmonary disease, which are considered smoking-associated chronic inflammatory conditions $(9,10)$. A previous study demonstrated that CCL20/CCR6 are involved in the metastasis of a variety of tumors, including pancreatic, hepatic, prostate and colorectal carcinomas (11). This suggests that CCL20 and CCR6 may also be involved in the occurrence and metastasis of lung adenocarcinoma.

In nonmalignant cells, extracellular signal-regulated kinase [ERK; also known as p44/42 mitogen-activated protein kinases (MAPKs)] signaling cascades are involved in regulating cell proliferation, survival and differentiation (12). Chemokine/chemokine receptor-mediated activation of ERK 
also serves a crucial role in cancer cell proliferation and invasiveness (13-15). Brand et al (16) reported that CCL20 activated Akt, ERK1/2 and stress-activated protein kinase/c-Jun $\mathrm{N}$-terminal kinase MAPKs, and increased interleukin-8 protein expression, resulting in a 2.6 -fold increase of cell migration as well as a significant increase of cell proliferation in colorectal cancer. The occurrence and development of lung cancer are also considered to be associated with the ERK signaling pathway (17).

However, the mechanisms of CCL20 and CCR6 in lung adenocarcinoma remain unclear. The present study was performed to evaluate the roles of the CCL20/CCR6 and the ERK signal pathway in lung adenocarcinoma growth.

\section{Patients and methods}

Study population. A total of 162 patients [62.75 \pm 9.76 years (mean age \pm standard deviation); 87 male and 75 female] with lung adenocarcinoma, whose diagnosis (pathological stage I or II, pre-operative assessments) was confirmed by histological examination between February 2009 and July 2011 at the Hebei General Hospital (Shijiazhuang, China), were enrolled in the present study. All the patients underwent pulmonary resection by video-assisted thoracoscopic surgery (VATS). The patients were divided into a recurrence group $(\mathrm{n}=50)$ and a non-recurrence group $(n=112)$ according to their recurrence and metastasis status within 2 years following surgery. Staging prior to and following surgery was based on histopathological analysis according to the International Union Against Cancer tumor-node-metastasis staging system (18). The study was approved by the Medical Ethics Committee on Human Research of Hebei General Hospital (no. 2005-123). Informed written consent was obtained from each patient. Patients were followed up for 2 years post-operatively.

Surgical procedures and sample collection. General anesthesia with double-lumen endotracheal intubation and one-lung ventilation was used for all patients during surgery. For the VATS procedure, three working ports were established for the insertion of thoracoscopic instruments; these were located at the 7th or 8th intercostal space at the mid-axillary line, the 4th or 5th intercostal space at the anterior axillary line, and the 8th or 9th intercostal space at the scapular line. Specimen bags were used for removing the samples. No muscles (latissimus dorsi or serratus anterior muscles) or ribs were cut. A proportion of the lung tissues were fixed in 10\% formalin, for $48-72 \mathrm{~h}$ at $4^{\circ} \mathrm{C}$ for immunohistochemistry, while others were stored at $-80^{\circ} \mathrm{C}$ for subsequent use in reverse transcription-quantitative polymerase chain reaction (RT-qPCR) and western blot analyses.

Immunohistochemistry and histological evaluation. The $5-\mu \mathrm{m}$-thick tissue sections were deparaffinized in xylene for 20 min twice and hydrated in a graded series of alcohol baths (100\% for 5 min twice, $95 \%$ for 5 min twice, $90 \%$ for $5 \min$ once and $80 \%$ for $5 \mathrm{~min}$ once). The sections were then washed with PBS, immersed in 3\% hydrogen peroxide for $15 \mathrm{~min}$ to block endogenous peroxidase activity at $37^{\circ} \mathrm{C}$ prior to being washed again with PBS and microwaved (medium power, $92-98^{\circ} \mathrm{C}$ ) for $20 \mathrm{~min}$ for antigen retrieval. Subsequently, the sections were incubated with goat anti-human CCL20 monoclonal antibody (dilution, 1:100; cat. no. AF360; R\&D Systems, Inc., Minneapolis, MN, USA) and mouse anti-human CCR6 monoclonal antibody (dilution, 1:200; cat. no. MAB195; R\&D Systems, Inc.) overnight at $4^{\circ} \mathrm{C}$. The sections were subsequently incubated with secondary anti-goat horseradish peroxidase-conjugated antibody (dilution, 1:500; cat. no. HAF019; R\&D Systems, Inc.) or secondary anti-mouse horseradish peroxidase-conjugated antibody (dilution, 1:500; cat. no. abs20002A; Dako; Agilent Technologies, Inc., Santa Clara, CA, USA), respectively, for $30 \mathrm{~min}$ at room temperature. The sections were washed with PBS then incubated for 3-5 min with 3,3'-diaminobenzidine (dilution, 1:1,000; cat. no. K3468 Dako; Agilent Technologies, Inc.), followed by counterstaining with hematoxylin for $30 \mathrm{sec}$ at room temperature and were dehydrated and mounted. Negative controls were performed in all cases by omitting the primary antibody.

The slides were independently evaluated and scored under a CX41 light microscope (magnification, x200; Olympus Corporation, Tokyo, Japan) by two pathologists without knowledge of clinical data who randomly captured and assessed 20 fields of view. The staining intensity was assigned a scored between 0 and 3, as follows: 0 , negative; 1 , weak; 2 , moderate; or 3 , strong. The percentages of positively stained tumor cells were counted and grouped into four levels $(0-25$, score $0 ; 26-50$, score $1 ; 51-75$, score $2 ; 76-100 \%$, score 3). Samples with $>50 \%$ positive cells were defined as having high expression. The total immunostaining score was calculated as the sum of each intensity score multiplied by the corresponding percentage, for example CCR6 index = (total staining intensity score of CCR6 x total positive tumor cells \% score for CCR6)/100.

Total RNA extraction and RT-qPCR of CCL20 and CCR6. In total, $50 \mathrm{mg}$ of each tissue sample was subjected to total RNA isolation using TRIzol reagent (Invitrogen; Thermo Fisher Scientific, Inc., Waltham, MA, USA) according to the manufacturer's protocol. To ensure that total RNA fulfilled the requirements for the qPCR, the purity and quantity of RNA for each sample was analyzed by nanodrop (a minimum A260/A280 ratio of $>1.8$ was applied for all samples) and RNA integrity was assessed by formaldehyde modified gel electrophoresis. cDNA was synthesized using PrimeScript ${ }^{\mathrm{TM}}$ RT reagent kit with gDNA Eraser (Takara Biotechnology Co., Ltd., Dalian, China). DNase (Takara Biotechnology Co., Ltd.) was used prior to the reverse transcription reaction. The following primer sequences were used: CCL20 forward, 5'-ATGTGCTGTACCAAGAGTTT-3' and reverse, 5'-CAA GTCTGTTTTGGATTTGC-3'; CCR6 forward, 5'-CCATTC TGGGCAGTGAGTCA-3' and reverse, 5'-AGCAGCATCCCG CAGTTAA-3'; GAPDH forward, 5'-ATCCCATCACCATCT TCCAG-3' and reverse, 5'-GAGTCCTTCCACGATACCAA-3'. qPCR was performed using a thermocycler for 35 cycles according to the following program: $5 \mathrm{~min}$ at $95^{\circ} \mathrm{C}, 15 \mathrm{sec}$ at $95^{\circ} \mathrm{C}, 30 \mathrm{sec}$ at $58^{\circ} \mathrm{C}$ and $30 \mathrm{sec}$ at $72^{\circ} \mathrm{C}$. The PCR mixture was prepared using Eastep ${ }^{\circledR}$ qPCR Master Mix (Shanghai Promega Biological Products Co., Ltd., Shanghai, China) according to the manufacturer's protocol. Expression levels of each mRNA were determined using the $2^{-\Delta \Delta C q}$ method (19) using GAPDH (Takara Biotechnology Co., Ltd.) as an endogenous control. The experiment was repeated three times. 
Western blot analysis of CCL2O and CCR6. Protein samples were prepared using radioimmunoprecipitation assay buffer. The total protein concentration was measured by using the BCA method and $60 \mu \mathrm{g}$ of each sample was subjected to $10 \%$ SDS-PAGE and then transferred to polyvinylidene fluoride membranes. Subsequent to blocking at room temperature for $1 \mathrm{~h}$ with $5 \%$ fat-free milk powder with $1 \%$ Triton $\mathrm{X}-100$ in TBS $(20 \mathrm{mmol} / 1$ Tris- $\mathrm{Cl}, 150 \mathrm{mmol} / \mathrm{l} \mathrm{NaCl}, \mathrm{pH} 7.4)$, the films were incubated at $4{ }^{\circ} \mathrm{C}$ overnight with antibodies against CCL20 (dilution, 1:200; cat. no. AF360; R\&D Systems, Inc.), CCR6 (dilution, 1:200; cat. no. MAB195; R\&D Systems, Inc.) and $\beta$-actin (dilution, 1:2,000; cat. no. sc-47778; Santa Cruz Biotechnology, Inc., Santa Cruz, CA, USA). Corresponding secondary anti-mouse horseradish peroxidase-conjugated antibody (dilution, 1:5,000; cat. no. abs20002A; DakoCytomation, Glostrup, Denmark) was then applied for $1 \mathrm{~h}$ at room temperature. The bands were detected on an X-ray film following the application of Pierce ECL Western Blotting Substrate (Thermo Fisher Scientific, Inc.). Relative optical density of all bands was analyzed by GelPro Analyzer (version 4.0; Media Cybernetics, Inc., Rockville, MD, USA).

A549 cell culture. The human alveolar epithelial A549 cell line was purchased from Cell Resource Center, Shanghai Institute of Life Sciences, Chinese Academy of Sciences (Shanghai, China) and grown in RPMI-1640 medium, supplemented with $1 \%$ penicillin/streptomycin and $10 \%$ fetal bovine serum. RPMI-1640 medium and 10\% fetal bovine serum were purchased from Thermo Fisher, Scientific, Inc. Cultures were maintained on tissue culture-treated petri dishes (BD Falcon; BD Biosciences, Franklin Lakes, NJ, USA) in a $5 \% \mathrm{CO}_{2}$ incubator at $37^{\circ} \mathrm{C}$.

Western blot analysis of phosphorylated (p)-ERK and ERK. Prior to western blot analysis, A549 cells were treated with CCL20 (500 ng/ml; R\&D Systems, Inc.) for 0, 5, 15, 30 and $60 \mathrm{~min}$. A549 cells with various treatments were harvested and lysed on ice in RIPA buffer (1\% Triton X-100, $150 \mathrm{mM} \mathrm{NaCl}$, 10 mM Tris-HCl, pH 7.4, 1 mM EDTA, 1 mM EGTA, pH 8.0, $0.2 \mathrm{mM} \mathrm{Na} 3 \mathrm{VO} 4,0.2 \mathrm{mM}$ phenylmethylsulfonyl fluoride and 0.5 \% NP-40; cat. no. 89900; Thermo Fisher Scientific, Inc.) containing a protease inhibitor. The total protein concentration was measured using the BCA method. Proteins $(60 \mu \mathrm{g}$ per lane) were subjected to SDS-PAGE using a $10 \%$ gel, and blotted onto nitrocellulose membranes (Hybond ECL; GE Healthcare, Chicago, IL, USA). Membranes were blocked by incubation in TBS containing 5\% nonfat dry milk and $0.1 \%$ Tween-20 for $2 \mathrm{~h}$ at room temperature and then incubated overnight at $4^{\circ} \mathrm{C}$ with rabbit anti-human p-ERK antibodies (dilution, 1:1,000; cat. no. sc-101760; Santa Cruz Biotechnology, Inc.), ERK antibodies (dilution, 1:1,000; cat. no. sc-292838; Santa Cruz Biotechnology, Inc.) and $\beta$-actin (dilution, 1:1,000; cat. no. sc-130656; Santa Cruz Biotechnology, Inc.). Blots were then washed with TBS/Tween-20 three times and incubated at room temperature for $1 \mathrm{~h}$ with horseradish peroxidase-conjugated goat anti-rabbit antibodies (cat. no. ab97051; Abcam, Cambridge, UK). The bands were detected on an X-ray film following application of Pierce ECL Western Blotting Substrate Thermo Fisher Scientific, Inc.). Relative optical density of all bands was analyzed using GelPro Analyzer 4.0.

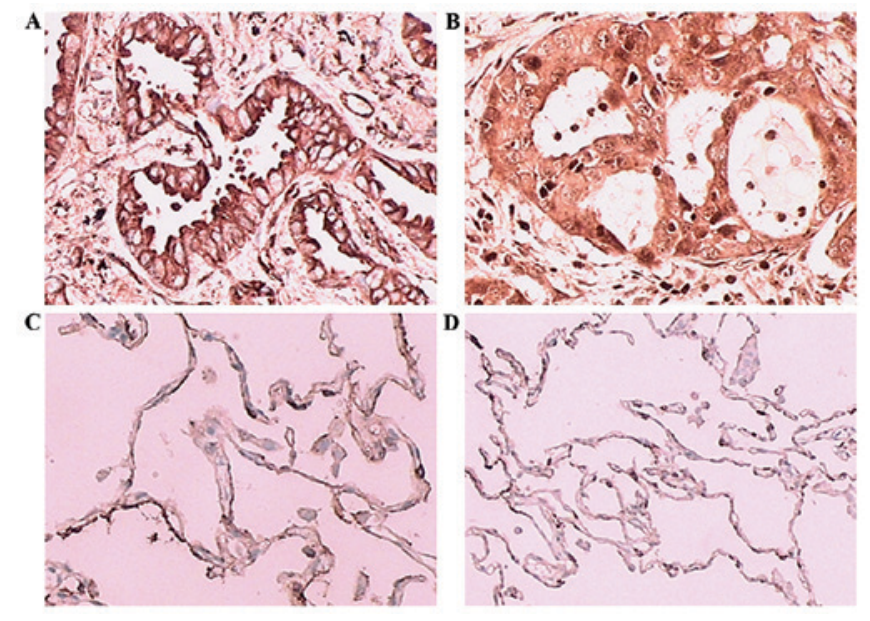

Figure 1. Immunohistochemical staining of CCL20 and CCR6 in lung adenocarcinoma tissue and cancer-adjacent tissues (magnification, x200). (A) CCL20 was expressed in the cell membrane and cytoplasm of lung adenocarcinoma tissue. (B) CCR6 was expressed in the cytoplasm of lung adenocarcinoma tissue. (C) CCL20 and (D) CCR6 in were scarcely expressed in carcinoma-adjacent tissues. Representative images are shown. CCL20, C-C motif chemokine ligand 20; CCR6, C-C motif chemokine receptor 6.

Colony formation assay. The A549 cells were treated with various concentrations of CCL20 (10, 50 and $250 \mathrm{ng} / \mathrm{ml})$ and PD98059 (20 $\mu \mathrm{l} / \mathrm{ml})$ (Cell Signaling Technology Biological Reagents Co., Ltd., Shanghai, China) at $37^{\circ} \mathrm{C}$ for 14 days. After macroscopically visible clones appeared, the culture was terminated; the cells were rinsed with PBS twice, fixed with methanol at $37^{\circ} \mathrm{C}$ for $15 \mathrm{~min}$ and subjected to Giemsa staining (Giemsa stain, modified; cat. no. GS1L-1L; Sigma-Aldrich; Merck KGaA, Darmstadt. Germany), performed according to manufacturer's protocol. The number of colonies was counted in 10 different fields under a CX41 light microscope (magnification, x100; Olympus Corporation).

Statistical analysis. Analyses were performed using SPSS 17.0 for Windows (SPSS, Inc., Chicago, IL, USA). Data are expressed as percentages or as the mean \pm standard deviation. The mean differences of continuous variables between groups were analyzed using an unpaired Student's t-test. The differences of categorical variables between groups were analyzed using the $\chi^{2}$ test. The mean differences of continuous variables among groups were analyzed using one-way analysis of variance, and the Newman-Keuls post hoc test was used in the event of a significant F-ratio. All significant tests were two-sided and $\mathrm{P}<0.05$ was considered to indicate a statistically significant difference.

\section{Results}

Expression of CCL2O and CCR6 in the non-recurrence and recurrence groups of patients with lung adenocarcinoma. As shown in Fig. 1, CCL20 was expressed in the cell membrane and cytoplasm, whereas CCR6 was predominantly expressed in the cytoplasm of lung adenocarcinoma tissues. In cancer-adjacent tissues, there was scarcely any expression of CCL20 or CCR6. The percentages of high-expression samples (with $>50 \%$ of cells stained) in the recurrence group were 76 and 66\%, respectively, which were significantly higher compared with those in 
Table I. CCL20 and CCR6 scores representing the percentage of positively stained tumor cells in the non-recurrence ( $\mathrm{n}=112$ ) and recurrence $(n=50)$ groups.

\begin{tabular}{|c|c|c|c|c|}
\hline \multirow{2}{*}{$\begin{array}{l}\text { Percentage of positive } \\
\text { tumor cells (score) }\end{array}$} & \multicolumn{2}{|c|}{$\begin{array}{l}\text { Non-recurrence group, no. of } \\
\text { patients (collective score) }\end{array}$} & \multicolumn{2}{|c|}{$\begin{array}{l}\text { Recurrence group, no. of } \\
\text { patients (collective score) }\end{array}$} \\
\hline & CCL20 & CCR6 & CCL20 & CCR6 \\
\hline $0-25 \%(0)$ & $81(0)$ & $80(0)$ & $9(0)$ & $13(0)$ \\
\hline $26-50 \%(1)$ & $22(22)$ & $25(25)$ & $3(3)$ & $4(4)$ \\
\hline $51-75 \%(2)$ & $5(10)$ & $4(8)$ & $8(16)$ & $7(14)$ \\
\hline $76-100 \%$ (3) & $4(12)$ & $3(9)$ & $30(90)$ & $26(78)$ \\
\hline Total & $112(44)$ & $112(42)$ & $50(109)$ & $50(96)$ \\
\hline
\end{tabular}

CCL20, C-C motif chemokine ligand 20; CCR6, C-C motif chemokine receptor 6.

Table II. CCL20 and CCR6 scores representing the staining intensity of samples in the non-recurrence $(\mathrm{n}=112)$ and recurrence $(\mathrm{n}=50)$ groups.

\begin{tabular}{lcccr}
\hline & \multicolumn{2}{c}{$\begin{array}{c}\text { Non-recurrence group, no. of } \\
\text { patients (collective score) }\end{array}$} & & \multicolumn{2}{c}{$\begin{array}{c}\text { Recurrence group, no. of } \\
\text { patients (collective score) }\end{array}$} \\
\cline { 2 - 3 } $\begin{array}{l}\text { Intensity } \\
\text { score }\end{array}$ & CCL20 & CCR6 & CCL20 & CCR6 \\
\hline 0 & $12(0)$ & $14(0)$ & $1(0)$ & $2(0)$ \\
1 & $72(72)$ & $61(61)$ & $3(3)$ & $1(1)$ \\
2 & $26(52)$ & $34(68)$ & $4(8)$ & $2(4)$ \\
3 & $2(6)$ & $3(9)$ & $42(126)$ & $55(135)$ \\
Total & $112(130)$ & $112(138)$ & $50(137)$ & $50(140)$ \\
\hline
\end{tabular}

CCL20, C-C motif chemokine receptor 20; CCR6, C-C motif chemokine receptor 6.

Table III. Expression rate of CCL20 and CCR6 in non-recurrence and recurrence groups.

\begin{tabular}{|c|c|c|c|c|}
\hline Group & High expression, $\mathrm{n}$ & Low expression, $\mathrm{n}$ & Total, $\mathrm{n}$ & High expression ratio, $\%$ \\
\hline \multicolumn{5}{|c|}{ Non-recurrence group } \\
\hline CCL20 & 9 & 103 & 112 & 8 \\
\hline CCR6 & 7 & 105 & 112 & 6 \\
\hline \multicolumn{5}{|c|}{ Recurrence group } \\
\hline CCL20 & 38 & 12 & 50 & 76 \\
\hline CCR6 & 33 & 17 & 50 & 66 \\
\hline
\end{tabular}

High expression was defined as positive staining of $>50 \%$ of the tumor cells in the sample. CCL20, C-C motif chemokine ligand 20; CCR6, C-C motif chemokine receptor 6 .

non-recurrence group ( 8 and $6 \% ; \mathrm{P}<0.001$ ). The sum of the staining indexes (total immunostaining score) of CCL20 and CCR6 in the recurrence group were 149.3 and 134.4, respectively, significantly higher than those in non-recurrence group, which were 57.2 and 58.0, respectively $(\mathrm{P}<0.001$; Tables I-III).

CCL2O and CCR6 IRNA and protein expression levels are higher in patients with recurrent compared with non-recurrent lung adenocarcinoma. Compared with the non-recurrence group, the mRNA expression levels of CCL20 and CCR6 were increased by $82 \%(\mathrm{P}<0.001)$ and $56 \%(\mathrm{P}<0.001)$, respectively, in the recurrence group (Fig. 2). Furthermore, compared with the non-recurrence group, the relative protein expression levels of CCL20 and CCR6, measured by western blotting, were increased by $282(\mathrm{P}<0.001)$ and $188 \%(\mathrm{P}<0.001)$, respectively, in the recurrence group (Fig. 3). 
Table IV. Colony formation by A549 cells in response to stimulation with increasing concentrations of CCL20 with or without the ERK inhibitor PD98059.

\begin{tabular}{lcrr}
\hline CCL20 concentration, $\mathrm{ng} / \mathrm{ml}$ & With PD98059 & $\mathrm{t}$ & P-value \\
\hline 0 & $160 \pm 15.2$ & $149 \pm 13.4$ & 1.5354 \\
10 & $280 \pm 16.8$ & $212 \pm 15.1$ & 8.5146 \\
50 & $325 \pm 17.5$ & $240 \pm 13.9$ & 10.7576 \\
250 & $440 \pm 19.8$ & $255 \pm 14.7$ & 21.2187 \\
\hline
\end{tabular}

CCL20, C-C motif chemokine ligand 20; ERK, extracellular signal-regulated kinase.

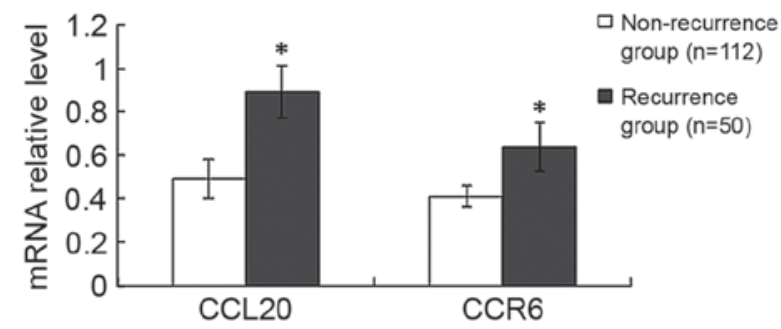

Figure 2. CCL20 and CCR6 mRNA expression relative to GAPDH, determined by reverse transcription-quantitative polymerase chain reaction, in lung adenocarcinoma tissues from patients with recurrent and non-recurrent disease. The mRNA levels of CCL20 and CCR6 were increased in the recurrence group compared with the non-recurrence group. ${ }^{*} \mathrm{P}<0.001$ vs. non-recurrence group. CCL20, C-C motif chemokine ligand 20; CCR6, C-C motif chemokine receptor 6.

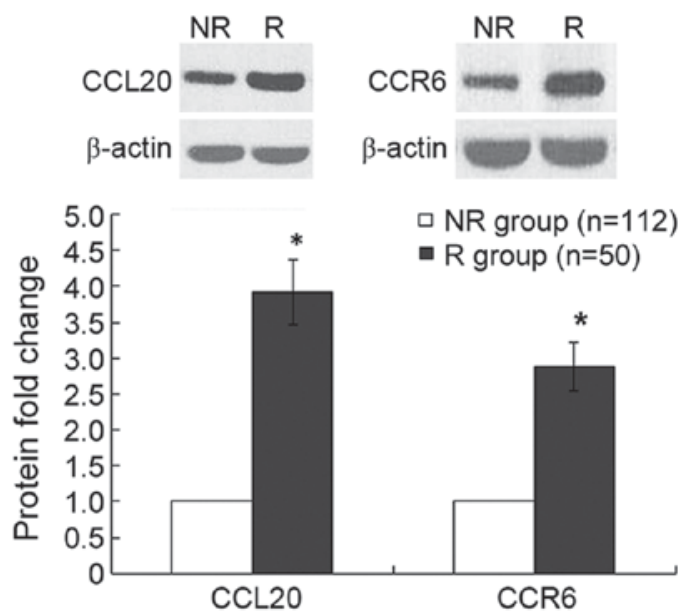

Figure 3. CCL20 and CCR6 protein expression by western blot analysis. The protein levels of CCL20 and CCR6 were increased in R group than in NR group of lung adenocarcinoma patients. Protein levels were normalized to the $\beta$-actin loading control and fold change was expressed relative to the NR group. ${ }^{*} \mathrm{P}<0.001$ vs. NR group. CCL20, C-C motif chemokine ligand 20; CCR6, C-C motif chemokine receptor 6; NR, non-recurrence; R, recurrence.

CCL2O induces ERK phosphorylation. Phosphorylation of ERK in tumor cells was detected at 5 and 15 min after stimulation of the cells with $500 \mathrm{ng} / \mathrm{ml}$ CCL20, while the level of overall ERK remained unaffected. The level of phosphorylation was significantly increased at 5 and 15 min compared with that at $0 \mathrm{~min}(\mathrm{P}<0.01)$, and markedly increased at $15 \mathrm{~min}$ compared with that at $5 \mathrm{~min}(\mathrm{P}<0.01)$. The $\mathrm{p}$-ERK protein level decreased at 30 and $60 \mathrm{~min}$ (Fig. 4).

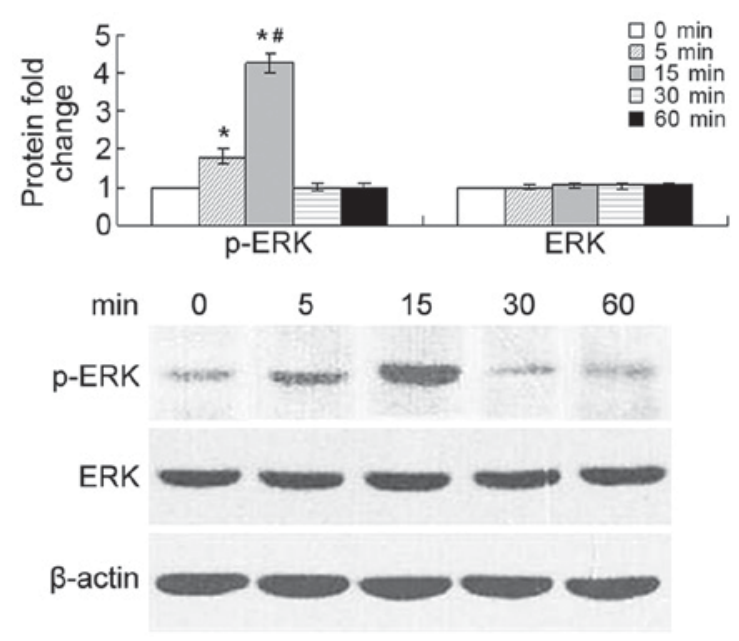

Figure 4. p-ERK and ERK protein expression by western blot analysis. CCL20 stimulation of A549 cells induced ERK phosphorylation 5-15 min after exposure, with no change in total ERK levels. The level of phosphorylation was increased significantly at 5 min compared with 0 min, and further increased significantly at $15 \mathrm{~min}$ compared with $5 \mathrm{~min}$. The p-ERK protein expression decreased at 30 and $60 \mathrm{~min}$, showing no significant different from the level at $0 \mathrm{~min}$. Protein levels were normalized to the $\beta$-actin loading control and fold change was expressed relative to the 0 min group. ${ }^{*} \mathrm{P}<0.01$ vs. $0 \mathrm{~min} ;{ }^{\#} \mathrm{P}<0.01$ vs. $5 \mathrm{~min}$. ERK, extracellular signal-regulated kinase; p-ERK, phosphorylated-ERK; CCL20, C-C motif chemokine ligand 20.

CCL20 promotes A549 cell colony formation, which is attenuated by treatment with an ERK inhibitor (PD98059). The colony formation was significantly increased following stimulation with 50 or $250 \mathrm{ng} / \mathrm{ml}$ CCL20 compared with 0 and $10 \mathrm{ng} / \mathrm{ml}$, in a dose-dependent manner ( $\mathrm{P}<0.01$; Table IV).

In the absence of CCL20 stimulation, there was no change in colony formation when cells were treated with specific ERK inhibitor compared with untreated cells $(\mathrm{P}=0.147)$, indicating no effect of PD98059 on the basal capacity of colony formation of A549 cells. However, treatment with PD98059 significantly attenuated the CCL20-induced increase in colony formation ability ( 0 vs. $20 \mu \mathrm{l} / \mathrm{ml} \mathrm{PD} 98059, \mathrm{P}<0.001$ for all concentrations of CCL20; Table IV).

\section{Discussion}

It is well-known that numerous types of cells, including cancer cells and leukocytes, express chemokines and their receptors (20-22). Tumor-derived chemokines perform an important role in the characteristic recruitment of leukocytes, including 
tumor-infiltrating lymphocytes, macrophages and dendritic cells, to the tumor environment (8). Chemokines and their receptors expressed by tumor cells enhance tumor growth, recurrence and metastatic potential (6,7). This suggests that CCL20/CCR6 may serve an important role in the development of lung cancer.

The present study showed that CCL20 was expressed in the cell membrane and cytoplasm of lung adenocarcinoma tissue, while CCR6 was only expressed in the cytoplasm. CCL20 and CCR6 expression levels in the recurrence group were significantly higher compared with those in the non-recurrence group. The mRNA and protein expression levels of CCL20 and CCR6 were also significantly increased in the recurrence group of lung adenocarcinoma tissue compared with the non-recurrence group. The abnormal expression of these molecules may lead to the occurrence and development of lung adenocarcinoma. Consistent with this finding, Kleeff et al (23) reported that, compared with normal human pancreatic tissues, CCL20 transcription in pancreatic ductal adenocarcinoma tissue is highly upregulated, as measured by northern blotting. Furthermore, another study that utilized RT-qPCR analysis and immunohistochemical staining demonstrated that CCL20 mRNA and protein were significantly overexpressed in breast adenocarcinoma compared with peritumoral areas (24). Shimizu et al (25) found that CCL20 and CCR6 were strongly expressed in chronically inflamed liver and hepatocellular carcinoma. These previous findings suggested that CCL20 and CCR6 interactions in the tumor environment may have a pro-carcinogenic function.

In the present study, the A549 cell line was selected to identify the potential mechanisms of CCL20/CCR6 interactions and the ERK signaling pathway in lung adenocarcinoma pathogenesis in vitro. Phosphorylation of ERK in tumor cells was detected following stimulation with CCL20, but there was no effect on the level of overall ERK. The colony formation ability of the cells was stimulated by CCL20 in a dose-dependent manner, and this effect was markedly attenuated by treatment with the ERK inhibitor PD98059, without any change in the basal (unstimulated) colony formation capacity of the cells treated with PD98059. Therefore, the CCL20-induced increase in cancerous cell colony formation was dependent, at least in part, on ERK phosphorylation and signaling. A study by Kimsey et al (26) also showed that co-localization of CCL20 and CCR6 promotes pancreatic cancer cell invasion into type IV collagen. This finding continues to highlight the importance of CCL20/CCR6 in the progression of pancreatic cancer. In colorectal cancer, tumor cells express CCL20 and CCR6 in a non-polarized manner, providing a basis for efficient autocrine and paracrine loops, and CCR6 is upregulated in colorectal cancer compared with normal colon mucosa (27). In another study, CCL20/CCR6 was shown to promote the growth of colorectal cancer cells through ERK phosphorylation (16). The present study demonstrated that CCL20/CCR6 serves a crucial role in NSCLC development, at least partially through the ERK signaling pathway.

However, the present study had several limitations, including the relatively small sample size and the requirement for validation studies in independent samples. Additional studies are required to clarify how the production of CCL20 was potentiated by cancerous cells.
In conclusion, the present study indicated that CCR6 and CCL20 may serve a role in lung adenocarcinoma, leading to proliferation and migration via autocrine or paracrine mechanisms. This effect is partially dependent on the ERK signaling pathway. The disruption of CCL20/CCR6 interactions may be a promising strategy in the treatment of cancer.

\section{Acknowledgements}

The authors would like to thank their colleagues in the Department of Thoracic Surgery (Hebei General Hospital) for collecting the samples and Dr Bing-jie Li (Hebei General Hospital) for providing technical assistance.

\section{References}

1. Parkin DM, Bray F, Ferlay J and Pisani P: Global cancer statistics, 2002. CA Cancer J Clin 55: 74-108, 2005.

2. Spiro SG and Silvestri GA: One hundred years of lung cancer. Am J Respir Crit Care Med 172: 523-529, 2005.

3. Radzikowska E, Głaz P and Roszkowski K: Lung cancer in women: Age, smoking, histology, performance status, stage, initial treatment and survival. Population-based study of 20 561 cases. Ann Oncol 13: 1087-1093, 2002.

4. Murphy PM, Baggiolini M, Charo IF, Hébert CA, Horuk R, Matsushima K, Miller LH, Oppenheim JJ and Power CA: International union of pharmacology. XXII. Nomenclature for chemokine receptors. Pharmacol Rev 52: 145-176, 2000.

5. Mantovani A, Allavena P, Sozzani S, Vecchi A, Locati M and Sica A: Chemokines in the recruitment and shaping of the leukocyte infiltrate of tumors. Semin Cancer Biol 14: 155-160, 2004.

6. Mantovani A: Chemokines in neoplastic progression. Semin Cancer Biol 14: 147-148, 2004.

7. Beider K, Abraham M, Begin M, Wald H, Weiss ID, Wald O, Pikarsky E, Abramovitch R, Zeira E, Galun E, et al: Interaction between CXCR4 and CCL20 pathways regulates tumor growth. PLoS One 4: e5125, 2009

8. Schutyser E, Struyf S and Van Damme J: The CC chemokine CCL20 and its receptor CCR6. Cytokine Growth Factor Rev 14: 409-426, 2003.

9. Bracke KR, Demedts IK, Joos GF and Brusselle GG: CC-chemokine receptors in chronic obstructive pulmonary disease. Inflamm Allergy Drug Targets 6: 75-79, 2007.

10. Demedts IK, Bracke KR, Van Pottelberge G, Testelmans D, Verleden GM, Vermassen FE, Joos GF and Brusselle GG: Accumulation of dendritic cells and increased CCL20 levels in the airways of patients with chronic obstructive pulmonary disease. Am J Respir Crit Care Med 175: 998-1005, 2007.

11. Ghadjar P, Rubie C, Aebersold DM and Keilholz U: The chemokine CCL20 and its receptor CCR6 in human malignancy with focus on colorectal cancer. Int J Cancer 125: 741-745, 2009.

12. Roberts PJ and Der CJ: Targeting the Raf-MEK-ERK mitogenactivated protein kinase cascade for the treatment of cancer. Oncogene 26: 3291-3310, 2007.

13. Huang YC, Hsiao YC, Chen YJ, Wei YY, Lai TH and Tang CH: Stromal cell-derived factor-1 enhances motility and integrin up-regulation through CXCR4, ERK and NF-kappaB-dependent pathway in human lung cancer cells. Biochem Pharmacol 74: 1702-1712. 2007.

14. Ganju RK, Brubaker SA, Meyer J, Dutt P, Yang Y, Qin S, Newman W and Groopman JE: The alpha-chemokine, stromal cell-derived factor-1alpha, binds to the transmembrane G-protein-coupled CXCR-4 receptor and activates multiple signal transduction pathways. J Biol Chem 273: 23169-23175, 1998.

15. Barbero S, Bonavia R, Bajetto A, Porcile C, Pirani P, Ravetti JL, Zona GL, Spaziante R, Florio T and Schettini G: Stromal cell-derived factor 1alpha stimulates human glioblastoma cell growth through the activation of both extracellular signal-regulated kinases 1/2 and Akt. Cancer Res 63: 1969-1974, 2003.

16. Brand S, Olszak T, Beigel F, Diebold J, Otte JM, Eichhorst ST, Göke B and Dambacher J: Cell differentiation dependent expressed CCR6 mediates ERK-1/2, SAPK/JNK, and Akt signaling resulting in proliferation and migration of colorectal cancer cells. J Cell Biochem 97: 709-723, 2006. 
17. Lee W, Jiang Z, Liu J, Haverty PM, Guan Y, Stinson J, Yue P, Zhang Y, Pant KP, Bhatt D, et al: The mutation spectrum revealed by paired genome sequences from a lung cancer patient. Nature 465 473-477, 2010.

18. Mountain CF: Revisions in the International System for staging lung cancer. Chest 111: 1710-1717, 1997.

19. Livak KJ and Schmittgen TD: Analysis of relative gene expression data using real-time quantitative PCR and the 2(-Delta Dleta C(T) method. Methods 25: 402-408, 2001

20. Wang JM, Deng X, Gong W and Su S: Chemokines and their role in tumor growth and metastasis. J Immunol Methods 220 1-17, 1998.

21. Balkwill $\mathrm{F}$ and Mantovani A: Inflammation and cancer: Back to Virchow? Lancet 357: 539-545, 2001.

22. Vicari AP and Caux C: Chemokines in cancer. Cytokine Growth Factor Rev 13: 143-154, 2002.

23. Kleeff J, Kusama T, Rossi DL, Ishiwata T, Maruyama H, Friess H, Büchler MW, Zlotnik A and Korc M: Detection and localization of MIP-3alpha/LARC/Exodus, a macrophage proinflammatory chemokine, and its CCR6 receptor in human pancreatic cancer. Int J Cancer 81: 650-657, 1999.
24. Bell D, Chomarat P, Broyles D, Netto G, Harb GM, Lebecque S, Valladeau J, Davoust J, Palucka KA and Banchereau J: In breast carcinoma tissue, immature dendritic cells reside within the tumor, whereas mature dendritic cells are located in peritumoral areas. J Exp Med 190: 1417-1426, 1999.

25. Shimizu Y, Murata H, Kashii Y, Hirano K, Kunitani H, Higuchi K and Watanabe A: CC-chemokine receptor 6 and its ligand macrophage inflammatory protein 3 alpha might be involved in the amplification of local necroinflammatory response in the liver. Hepatology 34: 311-319, 2001.

26. Kimsey TF, Campbell AS, Albo D, Wilson M and Wang TN Co-localization of macrophage inflammatory protein-3alpha (Mip-3alpha) and its receptor, CCR6, promotes pancreatic cancer cell invasion. Cancer J 10: 374-380, 2004.

27. Ghadjar P, Coupland SE, Na IK, Noutsias M, Letsch A Stroux A, Bauer S, Buhr HJ, Thiel E, Scheibenbogen C and Keilholz U: Chemokine receptor CCR6 expression level and liver metastasis in colorectal cancer. J Clin Oncol 24: 1910-1916, 2006. 